\title{
Em busca de novas explicações sobre a relação entre educação e desigualdade: o caso da Universidade Tecnológica de Nezahualcóyot* ${ }^{*}$
}

\section{In search of new explanations on the relationship between education and inequality: The case of the Nezahualcóyotl's Technological University}

\author{
Pedro Flores-Crespo ${ }^{* *}$
}

\begin{abstract}
RESUMO
Ao explicar a relação entre a desigualdade e a educação sob as perspectivas funcionalistas, corre-se o risco de deixar de debater a forma como os indivíduos atuam no interior das estruturas sociais. Esse artigo, portanto, se propõe a utilizar a perspectiva das capacidades humanas de Amartya Sen para explicar a relação entre desigualdade e educação superior no México. Para este estudo, foi escolhida a Universidade Tecnológica de Nezahualcóyotl (UTN), cujos egressos adquirem um tipo de capacidade (ou liberdade) que lhes permita recriar continuamente, até certo ponto, as formações sociais em que se inserem e atuam. Essa ação constitui um primeiro passo para a redução da desigualdade. No entanto, à medida que os jovens intervêm em seu mundo e traçam suas próprias rotas de desenvolvimento pessoal e
\end{abstract}

DOI: $10.1590 / 0104-4060.51381$

* Versão em português de Marina Feldman do artigo publicado por Pedro Flores-Crespo, "En busca de nuevas explicaciones sobre la relación entre educación y desigualdad. El caso de la Universidad Tecnológica de Nezahualcóyotl”, Revista Mexicana de Investigación Educativa, vol. 7, núm. 16, septiembre 2002, ISSN1405-6666, p. 537-576. Disponível em: <http://www.redalyc.org/ pdf/140/14001606.pdf > . Com autorização do autor em 3 abr. 2017 e dos editores da revista mexicana em 26 jun. 2017. Esse trabalho é parte de uma tese de doutorado sobre educação e desenvolvimento na Universidade de York, sob supervisão da professora Haleh Afshar.

** Universidade de York, 19 Farries Road, Epsom, KT17 1LP, Inglaterra. CE: pedrofc71@ yahoo.com 
profissional com o propósito de alcançar maior bem-estar, as oportunidades sociais e econômicas se restringem. Tal fato traz como consequência a divisão de um grupo de profissionais com aspirações similares, mas com níveis econômicos diversos, surgindo, assim, um novo tipo de desigualdade. Os estudantes, com um nível de renda mais alto, cumprem com maior facilidade suas aspirações quando comparados aos jovens que enfrentam limitações econômicas. Ainda que a UTN contribua de maneira substancial para a redução da desigualdade de capacidades, é necessário prestar atenção ao âmbito institucional, político e econômico que rodeia esta universidade para ampliar o entendimento da desigualdade dentro do campo educativo.

Palavras-chave: Igualdade de capacidades. Liberdade. Educação superior. Funcionalismo. Oportunidades sociais.

\begin{abstract}
Explaining the relationship between inequality and education from functionalist perspectives runs the risk of failing to discuss how individuals act within social structures. This article, therefore, proposes utilizing Amartya Sen's perspective of human capabilities to explain the relationship between inequality and higher education in Mexico. The Universidad Tecnológica de Nezahualcóyotl (UTN) was chosen for study since its graduates acquire a type of capability (or freedom) that allows them to recreate continually, up to a certain point, the social formations in which they live. This action comprises the first step in reducing inequality. However, to the degree these young people intervene in their world and chart their own routes for personal and professional development (with the purpose of attaining greater well-being), their social and economic opportunities contract. The result is a divided group of professionals with similar aspirations but different economic levels, and consequently a new type of inequality. Students with higher income levels meet their aspirations more easily than those who face economic restrictions. And although the UTN contributes substantially to reducing unequal capabilities, attention must also be paid to the university's institutional, political and economic setting in order to further the understanding of inequality in education.
\end{abstract}

Keywords: Equal capabilities. Freedom. Higher education. Functionalism. Social opportunities. 


\section{A educação, a desigualdade e o indivíduo: à guisa de introdução}

Se os seres humanos fossem puramente determinados e não seres "programados para aprender" não haveria por que, na prática educativa, apelarmos para a capacidade crítica do educando.

Paulo Freire, em Política e Educação $o^{1,2}$

Poderia a educação, formal ou informal, erradicar a desigualdade? Seria o processo educativo apenas um passo para reduzi-la? Ou, talvez, o processo de ensino-aprendizagem poderia reforçar as desigualdades estruturais? Esses são alguns questionamentos que nós, investigadores da educação, nos fazemos de modo recorrente e que motivaram o estudo dessa relação utilizando perspectivas diversas. María J. Freire (2000), por exemplo, analisou a relação entre a condição sociofamiliar dos estudantes e a igualdade de oportunidades educacionais ao mostrar que a taxa de acesso à universidade dos jovens, cujos pais eram analfabetos ou sem escolarização, melhorou consideravelmente entre 1990 e 1996, na região da Galícia, na Espanha. Ou seja, houve certa mobilidade social em consequência da expansão de oportunidades educacionais embora a ampliação da oferta educacional envolva também fatores adicionais, que estão relacionados com certo tipo de desigualdade. Ayalon e Gamoran (2000) indicam que ampliar o acesso à educação implica também numa diferenciação do currículo, o que por sua vez pode produzir desigualdades em termos de resultados educacionais. Outro fator que chama a atenção sobre a oferta educacional e a desigualdade é o de Samuel Bowles, quando argumenta que, nos Estados Unidos, as escolas não evoluíram em direção à igualdade, visto que apenas atendem "as necessidades de mão de obra qualificada e disciplinada dos empregadores capitalistas ${ }^{3 "}$, e dessa maneira se convertem em mecanismos de controle social, úteis para a estabilidade política (BOWLES, 1977, p. 137).

No caso do México, Carlos Muñoz Izquierdo sustenta que se, por um lado, o desenvolvimento educacional se condiciona pelas desigualdades inter-regionais, estas tenderiam a se ampliar. Por outro lado, se a política educacional

1 As citações em língua estrangeira foram traduzidas por Marina Feldman.

2 Nota da tradutora - As traduções desta obra de Freire (1996) foram retiradas da versão original em português. FREIRE, P. Política e Educação. São Paulo: Cortez, 2001.

3 Nota da tradutora - Traduzido a partir da citação original utilizada pelo autor: "las necesidades de mano de obra calificada y disciplinada de los empleadores capitalistas”. 
"tem um comportamento contrário" às disparidades regionais, então as brechas entre entes federativos poderiam ser reduzidas (MUÑOZ IZQUIERDO, 1996, p. 133).

À luz dos argumentos de M. J. Freire, Ayalon e Gamoran, Bowles e Muñoz Izquierdo, pode-se dizer que os governos, ao prover a população com maiores oportunidades educacionais, poderiam gerar efeitos relacionados com movimentos intergeracionais ascendentes e, talvez, reduções relevantes nas disparidades regionais. Contudo, o esforço educacional poderia propiciar níveis diferenciados no desempenho acadêmico dos estudantes (AYALON; GAMORAN, 2000), ampliação da desigualdade inter-regional (MUÑOZ IZQUIERDO, 1996) ou controle social (BOWLES, 1977). Parece, portanto, que, ao se buscar igualar as oportunidades educacionais, poderiam ser geradas desigualdades de outro tipo. Sobre tal questão, Lorenza Villa Lever (1996, p. 422) diz que, no México, "o princípio constitucional da igualdade de oportunidades para todos tem mostrado fortes fraturas nos últimos tempos"

Outra observação que deriva das perspectivas descritas anteriormente é que não há um consenso em que se indique a que tipo de igualdade estamos nos referindo. Enquanto M. J. Freire analisa a igualdade de oportunidades, Ayalon e Gamoran se concentram nas desigualdades dos resultados educacionais, e Muñoz Izquierdo fala sobre desigualdades educativas que poderiam ser determinadas pelas desigualdades sociais. Adiante se aludirá ao conceito de desigualdade utilizado neste trabalho, por ora se faz necessário ressaltar que, segundo Muñoz Izquierdo (1996), o estudo das relações entre os sistemas educativos e as estruturas econômicas, culturais e sociais se apoiam basicamente em dois paradigmas, o funcional e o dialético. Este autor explica que:

[O] primeiro supõe que as formações sociais se apoiam no consenso e se reproduzem a partir de relações harmônicas entre os diversos setores integrantes da sociedade. O segundo supõe, por outro lado, que em qualquer formação social subjazem diversos conflitos entre as classes integrantes da mesma, e que da resolução ou do acirramento destes conflitos depende a conservação da ordem estabelecida ou a transformação das bases em que essa última se apoia5. (MUÑOZ IZQUIERDO, 1996, p. 124).

4 Nota da tradutora - Traduzido a partir da citação original utilizada pelo autor: "el principio constitucional de igualdad de oportunidad para todos ha mostrado en los últimos tempos fuertes fracturas".

5 Nota da tradutora - Traduzido a partir da citação original utilizada pelo autor: "[El] primero supone que las formaciones sociales se apoyan en el consenso y se reproducen a partir de las relaciones armónicas entre los diversos sectores integrantes de la sociedad. El segundo supone, en 
Diversas posições epistemológicas ${ }^{6}$ poderiam se relacionar com estes dois "paradigmas" para explicar a relação entre educação e desigualdade. Uma destas posições seria o estruturalismo ${ }^{7}$ que, segundo Anthony Giddens (1989), tem notáveis semelhanças com o funcionalismo. Esses dois enfoques, afirma Giddens, enfatizam a importância do conjunto social sobre suas partes individuais (i.e., seus atores constitutivos ou os sujeitos humanos). Segundo o Dicionário Oxford de Sociologia (1998), o estruturalismo transforma a noção dos indivíduos, que podem ser considerados mais como produtos das relações sociais do que como autores da realidade social.

Analisar a relação entre educação e desigualdade sob a visão funcional ou dialética cria uma controvérsia em que se dedica demasiada atenção à formação das estruturas sociais em detrimento de um aspecto complementar que se refere à agência ou intervenção dos seres humanos (human agency). Coleman (1997) enxerga essa carência como um "grave erro" dos enfoques sociológicos para descrever e explicar a ação. A ideia de que o ator é moldado (usando os termos de Coleman) pelo seu ambiente e que não tem capacidade própria que lhe dê direção é também questionada por Anthony Giddens na sua teoria da estruturação. Argumenta que as atividades sócio-humanas e os fenômenos autorreprodutivos estão em constante movimento ${ }^{8} \mathrm{e}$, por isso, não são criados pelos atores sociais, mas continuamente recriados pelos meios através dos quais eles mesmos se expressam como atores (GIDDENS, 1989). Então, que importância tem a agência humana para a análise da relação entre educação e desigualdade? Em primeiro lugar, tem de se dizer que a intervenção dos indivíduos, de acordo com Giddens $(1989$, p. 9), se refere "à capacidade de fazer as coisas e não à intenção", ou seja, a ação pode ser considerada como uma liberdade individual. Em segundo lugar, há de se recordar que Paulo Feire afirmava que a educação "é uma forma de intervenção no mundo", por isso o exercício de educar não poderia ser uma prática neutra. Além disso, o pedagogo brasileiro pensava ser incorreto qualificar a educação como uma "tarefa apenas reprodutora da ideologia dominante" (FREIRE, 1999, p. 95), agregando:

cambio, que en cualquier formación social subyacen diversos conflictos entre las clases integrantes de la misma, y que de la resolución o acrecentamiento de tales conflictos depende la conservación del orden establecido o la transformación de las bases en que este último se apoya (MUÑOZ IZQUIERDO, 1996, p. 124).

6 Outros enfoques relacionados com o funcionalismo e o estruturalismo são o historicismo, o determinismo econômico ou o "reducionismo biológico", que explica os fenômenos sociais e culturais com base nos enfoques biológicos, como a teoria da evolução de Darwin (DICIONÁRIO OXFORD DE SOCIOLOGIA, 1998).

7 O professor Muñoz Izquierdo reconhece que as teses que menciona sobre o paradigma dialético são de caráter estrutural.

$8 \mathrm{O}$ termo em inglês usado por Giddens é recursive. 
Para que os seres humanos se movam no tempo e no espaço no cumprimento de sua vocação, na realização de seu destino, obviamente não no sentido comum da palavra, como algo a que se está fadado, como sina inexorável, é preciso que se envolvam permanentemente no domínio político, refazendo sempre as estruturas sociais, econômicas, em que se dão as relações de poder e se geram as ideologias. (FREIRE, 1996, p. 13 , grifos do autor).

São claras as coincidências entre a perspectiva de Freire e a visão sociológica de Giddens, portanto se poderia sustentar que existe a possibilidade de que algum estudante, independentemente de sua origem social, possa, mediante suas ações, superar a estrutura social em que existe e atua. É importante considerar que os seres humanos não estão totalmente determinados a desempenhar um papel específico como resultado de sua herança social, econômica, cultural ou política.

Outro argumento relevante sobre a dualidade entre estrutura e a agência é o de Amartya Sen, especialista no estudo da pobreza e da desigualdade, que enfatiza que "existe uma profunda complementariedade entre a agência individual e as condições sociais existentes", por isso: "É importante reconhecer ao mesmo tempo o lugar fundamental que ocupa a liberdade individual $e$ a força das influências sociais sobre o limite e o alcance desse tipo de liberdade" (SEN, 1999, p. XII, grifos do autor).

Para Sen, a ação dos seres humanos poderia ir em uma direção que aponte para o melhoramento de suas condições de vida já que "o bem-estar ${ }^{10}$ das pessoas está influenciado por sua agência" (SEN, 1985a, p. 5). Apesar disso, esse autor enfatiza o fato de que "a liberdade de agência que possuímos individualmente está inevitavelmente limitada e restrita pelas oportunidades sociais, políticas e econômica a que temos acesso ${ }^{11}$ " $(\text { SEN, 1999, p. XI-XII) })^{12}$.

9 Nota da tradutora - Traduzido a partir da citação original utilizada pelo autor: "Es importante reconocer al mismo tiempo el lugar fundamental que ocupa la libertad individual $y$ la fuerza de las influencias sociales sobre el límite y el alcance de este tipo de libertad".

10 Para Sen (1985), o bem-estar se entende como base em que as pessoas podem fazer ou ser, ou seja, na forma em que funcionam. A isso chama de functionings, ou realizações, as quais podem ser tanto atividades (comer, ler etc.) ou estados de existência (estar nutrido, não sentir vergonha pelo tipo de roupas e sapatos que se usa etc.)

11 Nota da tradutora - Traduzido a partir das citações originais utilizadas pelo autor: "el bienestar de las personas está influido por su agencia" e "la libertad de agencia que poseemos individualmente está inevitablemente limitada y restringida por las oportunidades sociales, políticas y económicas a las que tenemos acceso".

12 Um ponto de vista interessante sobre agência humana e gênero pode ser encontrado em ROWLANDS (1977). Questioning empowerment: working with women in Honduras, Oxford: OXFAM, 1997. 
Dentro da perspectiva de Sen, a educação tem um papel relevante, pois, por um lado, pode incentivar os indivíduos "a atuar ou negar-se a atuar e a decidir atuar de uma forma ou de outra ${ }^{13}$ " (SEN, 1999, p. 190); enquanto, por outro, forma parte das oportunidades sociais a que os indivíduos têm acesso (ver "As liberdades instrumentais") $)^{14}$.

Poucas são as investigações educacionais sobre a complementaridade de que fala Sen, ou da teoria da estruturação de Giddens. Tampouco são conhecidos estudos que retomem a visão pedagógica de Freire relacionando-a com as ideias de Amartya Sen ou com as de Giddens; apesar de ter sido detectada a necessidade deste tipo de enfoque analítico. Em seu estudo sobre Desigualdade social, educação superior e sociologia no México, Jorge Bartolucci (1994, p. 34-35) sugere questionar a ideia de que os fatores sociais podem exercer uma "influência decisiva" por sobre a da "interação circunstancial entre seus membros", e adverte ser necessário "revisar seriamente a premissa de que um grupo ou classe social possa impor suas condições como resultado da supremacia econômica, ideológica ou política que deriva de sua posição na sociedade ${ }^{15}$ ".

Esse ensaio analisa, com base nas considerações anteriores, a relação entre educação e desigualdade por meio de um enfoque distinto ao estrutural e ao funcional. Para isso, as ideias de Amartya Sen sobre desigualdade são discutidas em relação com um grupo de indivíduos dentro de um contexto específico. Estudar o que fazem os egressos da Universidade Tecnológica de Nezahualcóyotl, dentro de um entorno marcado por severas desvantagens sociais e econômicas, mostra, entre outras coisas, a relevância dos enfoques não estruturais para explicar a desigualdade no campo da investigação educacional.

13 Nota da tradutora - Traduzido a partir da citação original utilizada pelo autor: "actuar o a negarse actuar y a decidir actuar de una forma o de otra".

14 Alguns autores como Unterhalter (2001) assinalam que a educação é uma área pouco "teorizada" nos aportes de Sen, ainda que seja necessário esclarecer que isso talvez se explique por uma falta de trabalho empírico nesse sentido e não por falta de atenção do professor hindu a essa variável. Ao ter desenvolvido um enfoque humanista - e não utilitarista - para explicar a desigualdade e a pobreza, Sen centra sua atenção, constantemente, na educação e lhe dá um tratamento não menos eloquente. Veja-se, por exemplo, Sen (1996, 1999, capítulo 12) ou os diversos relatórios do Programa de Desenvolvimento Humano das Nações Unidas (UNDP) que incluem índices baseados em variáveis educacionais e nos quais Amartya Sen participou como assessor.

15 Nota da tradutora - Traduzido a partir da citação original utilizada pelo autor: "revisar seriamente la premisa de que un grupo o clase social logre imponer sus condiciones como resultado de la supremacía económica, ideológica o política que se deriva de su posición en la sociedad”. 


\section{Igualdade de quê?}

Em seu livro Inequality Reexamined, Amartya Sen (1992) inicia sua discussão perguntando-se igualdade de quê? Esse questionamento também é relevante para o presente trabalho, pois, como se pontuou, há uma ampla gama de termos para se referir à desigualdade no campo da investigação educacional (MUÑOZ IZQUIERDO, 1996; FREIRE, 2000; AYALON; GAMORAN, 2000). Alguns teóricos sustentam que, para avançar no entendimento dessa área de estudo, é necessário colocar maior atenção à complementaridade entre a agência humana e as condições sociais existentes. Afortunadamente Sen constrói uma sólida base intelectual para tanto.

Ao falar em desigualdade, o professor hindu ressalta o fato de que os seres humanos começam a vida com diferentes responsabilidades e legados de riqueza herdada. Mais além vivemos em diversos ambientes naturais e diferimos também quanto às características pessoais; portanto, a desigualdade de uma dessas variáveis (ex.: renda) poderia nos levar na direção oposta à desigualdade de outra delas (ex: habilidade funcional ou o bem-estar). Por exemplo, uma pessoa inválida não pode funcionar da mesma maneira que uma pessoa apta fisicamente, mesmo que ambas tenham o mesmo nível de renda (SEN, 1992). Dessa forma, "uma das consequências da diversidade humana é que a igualdade, em algum aspecto, tende a ir junto com a desigualdade em outro ${ }^{16 "}$ (SEN, 1992, p. 20). Então, como solucionar esse paradoxo e responder à pergunta "igualdade de quê"? Para Alex Callinicos, Amartya Sen é um teórico que não busca igualar alguma variável e, desde um ponto de vista filosófico, relacionar de maneira eloquente a liberdade e a igualdade (CALLINICOS, 2000). A liberdade, diz Sen (1993, p. 23), está entre "os campos de aplicabilidade da igualdade 17" e está, por sua vez, entre os possíveis padrões de distribuição da liberdade. Porém, poderíamos falar, então, de igualdade de liberdades? Ao ter revisado diferentes correntes de pensamento e o trabalho de diversos autores (John Rawls, Ronald Dworkin, G. A. Cohen, A. B. Atkinson, Robert Nozick, entre outros), Amartya Sen desenvolveu o enfoque das capacidades humanas (Human Capabilities Approach) para explicar a desigualdade e a pobreza no mundo.

16 Nota da tradutora - Traduzido a partir da citação original utilizada pelo autor: "una de las consecuencias de la diversidad humana es que la igualdad, en algún aspecto, tiende a ir junto con la desigualdade en otro".

17 Nota da tradutora - Traduzido a partir da citação original utilizada pelo autor: "los campos de aplicabilidad de la igualdad". 
O enfoque de Sen teve um grande impacto na literatura das ciências sociais aplicadas, "o que não é usual para uma teoria política normativa ${ }^{18 "}$ segundo Callinicos (2000, p. 59). Exemplo disso é a participação de Amartya Sen no Programa de Desenvolvimento Humano das Nações Unidas (UNDP, por sua sigla em inglês) em que foi figura chave - juntamente com outros economistas reconhecidos, como o paquistanês Mahbub ul Haq - no desenvolvimento dos Índices de Desenvolvimento Humano (IDH) ${ }^{19}$ (UNDP, 2000).

A perspectiva das capacidades humanas é produto de um amplo estudo e envolve uma série de aspectos que o fazem relevante para a análise social e para as disciplinas que tenham a ver com os seres humanos. A educação é, sem dúvida, um desses ramos do conhecimento que pode aplicar, como uma alternativa, a perspectiva do economista hindu.

É necessário destacar que a aplicação desse enfoque envolve "toda uma multiplicidade de considerações que pedem nossa atenção ${ }^{20 "}$ e, por isso, as avaliações tem de serem feitas com "sensibilidade" a tais considerações (SEN, 1999, p. 85). A maneira de fazê-lo dependerá do tipo de investigação que se realize e de seus objetivos, já que "não está claro se existe um caminho real para avaliar a política econômica ou social21", como diz o Nobel de Economia (SEN, 1999, p. 85). Há dois marcos básicos para avaliar a desigualdade de capacidade: 1) os resultados ou realizações (functionigs) das pessoas e 2) a liberdade que essas têm para alcançar suas realizações. Na sequência, se explicam ambos os aspectos.

\section{As bases das capacidades humanas}

Segundo Sen (1999), o conceito de realizações tem raízes aristotélicas, porque a vida se sustenta nas diversas coisas que uma pessoa pode valorizar,

18 Nota da tradutora - Traduzido a partir da citação original utilizada pelo autor: "lo que es inusual de alguna teoría política normativa"

19 O IDH é um índice composto por três indicadores: longevidade, medido pela esperança de vida ao nascer, realização educacional, medida pelo grau de alfabetismo entre adultos e a taxa bruta de matrícula na educação primária, secundária e terciária; e o tipo de vida representado pelo PIB per capita. (UNDP, 2000, p. 279).

20 Nota da tradutora - Traduzido a partir da citação original utilizada pelo autor: "toda una multitud de consideraciones que reclaman nuestra atención. y por eso las evaluaciones tienen que hacerse con sensibilidad".

21 Nota da tradutora - Traduzido a partir da citação original utilizada pelo autor: "no está claro que exista un camino real para evaluar la política económica o la social”. 
fazer ou $\operatorname{ser}^{22}$. As realizações podem ser estados de existência ou atividades dos indivíduos e podem variar de um nível elementar, como seria estar nutrido e não sofrer de doenças que podem ser prevenidas, até estados mais complexos, como ser capaz de participar da vida em comunidade e "respeitar-se a si mesmo" (SEN, 1999, p. 75).

Para definir uma realização, teria de se perguntar do que uma pessoa é capaz, ou não, de fazer e o que essa pessoa pode ou não ser; ou seja, indagar o estado de existência dos indivíduos. Para o caso da educação e usando as realizações como uma base, poderíamos investigar as coisas que, por exemplo, um jovem pode fazer com o conhecimento adquirido em uma escola técnica, assim como saber se está satisfeito, ou não, com o fato de ser um profissional.

Outra ilustração - certamente existe uma infinidade -, sobre as realizações no campo educacional, é a de Paulo Freire que, em seu livro Política e educação, narra o caso de Carlinha: uma menina pobre que, "rondando a escola", perambulava pelas ruas de São Paulo, seminua e "sujo na cara, que escondia sua beleza" (FREIRE, 1996, p. 57). Nessas condições, diz Freire, Carlinha era alvo da zombaria das outras crianças e dos adultos, até que um dia a professora Madalena Freire sugeriu à avó de Carlinha que lhe banhasse e pusesse um mínimo de roupa. A avó seguiu as instruções da professora e, passados alguns dias, a cara limpa dessa menina foi atraindo a atenção dos meninos. Assim, Carlinha começou a confiar em si mesma, "se descobriu", diz Paulo Freire, e então a menina recuperou um espaço, "o de sua dignidade". Na conclusão dessa história, o pedagogo brasileiro diz que será mais fácil para Carlinha, no dia de amanhã, reconhecer-se como membro de uma classe, "a trabalhadora, em busca de melhores dias" (1996, p. 57). Assim, as realizações, de que fala Sen, tomaram forma em um novo estado de existência de Carlinha (a confiança em si mesma e sua dignidade), e isso lhe servirá para buscar no futuro o seu bem-estar ou, nas palavras de Freire, "melhores dias".

Voltando à discussão sobre o enfoque teórico de Amartya Sen, esse autor sustenta que do conjunto das realizações depende o bem-estar dos indivíduos, "mais que das características dos bens que possuii"3" (SEN, 1985b, p. 5). Os bens, diz Sen (1985b), podem ser transformados em realizações e converter-se, portanto, em meios de bem-estar e não em seus fins; no entanto, nesse processo de conversão também tem de se levar em conta as diferenças interpessoais. Isso é congruente com a ideia de reconhecer e entender a diversidade humana

22 Sobre tal justificativa, Amartya Sen recomenda revisar a Ética à Nicômaco, de Aristóteles, em que fala da "vida em termos de atividade" (SEN, 1992, p. 39).

23 Nota da tradutora - Traduzido a partir da citação original utilizada pelo autor: "más que de las características de los bienes que se poseen". 
para explicar a desigualdade. Vejamos um exemplo: a comida, diz Sen, que certo grupo de pessoas pode possuir é um bem, mas estar adequadamente nutrido depende de outros fatores, tais como os processos metabólicos, o porte físico, a idade, o sexo ("e se é mulher, se está grávida e em etapa de lactação" (SEN, 1992), as atividades, as condições climáticas, a presença de doenças parasitárias, o acesso a serviços médicos, o conhecimento nutricional e demais influências (SEN, 1992). Dito isto, Sen vai além em sua análise ao afirmar que a "variabilidade interpessoal da relação entre bens e relações ganha importância central para questões de política pública' ${ }^{24 "}$ (SEN, 1985a, p. 199). Ou seja, não apenas tem de se reconhecer essas diferenças entre os indivíduos, mas também desenhar e implantar ações para que as pessoas alcancem um número maior de realizações já que:

A capacidade de uma pessoa se refere às diversas combinações de realizações que pode conseguir. Portanto, a capacidade é um tipo de liberdade: a liberdade fundamental para conseguirmos diferentes combinações de realizações (ou, em termos menos formais, a liberdade para conquistas de diferentes estilos de vida) [...] uma pessoa que jejue pode alcançar os mesmos resultados funcionais, no que se refere a comer ou a nutrir-se, que uma pessoa desfavorecida que se veja obrigada a passar fome, mas a primeira possui um "conjunto de capacidade" diferente da segunda (a primeira pode decidir comer bem e estar nutrida, enquanto a segunda não) ${ }^{25}$. (SEN, 1999, p. 175).

De acordo com Sen, pode-se afirmar que a liberdade para alcançar realizações se forma do "conjunto de capacidade", que são, em outras palavras, suas oportunidades reais. Mas, como complemento dessas oportunidades reais, se deve considerar outro aspecto a que Sen chama de liberdades instrumentais. Esse tipo

24 Nota da tradutora - Traduzido a partir da citação original utilizada pelo autor: "variabilidad interpersonal de la relación entre bienes y realizaciones se vuelve de importancia central para cuestiones de política pública".

25 Nota da tradutora - Traduzido a partir da citação original utilizada pelo autor: "La capacidad de una persona se refiere a las diversas combinaciones de realizaciones que puede conseguir. Por lo tanto, la capacidad es un tipo de libertad: la libertad fundamental para conseguir distintas combinaciones de realizaciones (o, en términos menos formales, la libertad para lograr diferentes estilos de vida) [...] una persona que ayune puede lograr los mismos resultados funcionales en lo que se refiere a comer o a nutrirse que una persona desfavorecida que se vea obligada a pasar hambre, sólo que la primera tiene un conjunto de capacidades diferente al de la segunda (la primera puede decidir comer bien y estar nutrida, mientras que la segunda no). 
de liberdade nos conduz a colocar maior atenção nos esforços que os governos e a sociedade em geral têm de fazer para expandir as capacidades humanas. Como se observa, as ideias sobre liberdade do professor hindu não são meras abstrações.

\section{As liberdades instrumentais: um aditivo para as capacidades humanas}

Conforme dito anteriormente, o enfoque das capacidades humanas pode ser utilizado de maneiras distintas e avaliado com atenção às realizações dos indivíduos e à sua liberdade para alcançá-las. Ainda que aparentemente simples, a perspectiva baseada nas liberdades tem "um alcance enorme, lhe permitindo prestar uma atenção valorativa a toda uma variedade de aspectos importantes ${ }^{26}$ " (SEN, 1999, p. 86). As liberdades instrumentais são um dos aspectos que se necessita incluir na análise da educação e da desigualdade, não sendo outra coisa além da "capacidade geral das pessoas para viver mais livremente ${ }^{27}$ " (SEN, 1999, p. 38). Para esse crítico, existem cinco tipos de liberdades: 1) as liberdades políticas, 2) as facilidades econômicas, 3) as oportunidades sociais, 4) as garantias de transparência e 5) a segurança protetora.

As liberdades políticas, segundo Sen, se referem às oportunidades que as pessoas têm para decidir quem deve governar e com que princípios, e incluem a possibilidade de escrutínio e crítica às autoridades, a liberdade de expressão política e de imprensa sem censura, a liberdade para eleger entre diferentes partidos políticos etc.

Para o autor, as facilidades econômicas são as oportunidades que os indivíduos têm para utilizar recursos econômicos com o propósito de consumo, produção ou intercâmbio. Nessa categoria entrariam as titularidades (entitlements) econômicas que uma pessoa tem, as quais dependem dos recursos que possua ou a que tenha acesso, como por exemplo, os créditos e microcréditos. Mais além, há que se incluir o trabalho, já que, "para uma boa parte da humanidade, sua força de trabalho é sua única e significativa propriedade ${ }^{28 "}$ (SEN, 1999, p. 162).

Por oportunidades sociais, Sen se refere às condições que a sociedade estabelece para obter educação, saúde etc., e que influem na liberdade substan-

26 Nota da tradutora - Traduzido a partir da citação original utilizada pelo autor: "un enorme alcance y le permiten prestar una atención valorativa a toda una variedad de aspectos importantes".

27 Nota da tradutora - Traduzido a partir da citação original utilizada pelo autor: "la capacidad general de las personas para vivir más libremente".

28 Nota da tradutora - Traduzido a partir da citação original utilizada pelo autor: "para una buena parte de la humanidad, su fuerza de trabajo es su única y significativa dotación". 
cial do indivíduo para viver melhor. O autor argumenta que essas atividades são importantes, tanto para levar uma vida saudável como para participar de modo eficaz nas atividades econômicas e políticas.

A respeito da quarta categoria, chamada de garantias de transparência, Amartya Sen alude à necessidade de abertura ou de confiança que os indivíduos esperam e com que a sociedade funciona.

A quinta e última oportunidade, a segurança protetora, é essencial já que proporciona uma rede de proteção social que impede que a população afetada caia em uma miséria maior, na inanição e, em último caso, na morte. Essa liberdade instrumental "deve existir, não importante quão bem funcione um sistema econômico ${ }^{29 "}$ " (SEN, 1999, p. 39-49).

Todas essas vias práticas da liberdade são importantes para discutir a relação entre educação superior e desigualdade; todavia, por questão de espaço, esse trabalho somente analisa duas: as facilidades econômicas e as oportunidades sociais. Mais além, tais liberdades estão mais relacionadas com as atividades que desempenham os sujeitos de análise selecionados (egressos universitários).

Uma vez descritos alguns dos fundamentos do enfoque de capacidades humanas de Amartya Sen, valeria a pena discutir se suas proposições teóricas podem ser aplicadas a um grupo de pessoas com características específicas.

\section{Metodologia}

\section{O caso estudado}

Ao longo deste estudo, vem-se afirmando que uma base primária para avaliar a igualdade das capacidades dos indivíduos são suas realizações, sendo, portanto, necessário identificar sujeitos de análise concretos. Como se mencionou a princípio, foi selecionada, como caso de estudo, a Universidade Tecnológica de Nezahualcóyotl (UTN) que, junto com a de Tula e a de Aguascalientes, foi uma das primeiras instituições deste tipo no México.

Segundo a Coordenação Geral de Universidades Tecnológicas (CGUT), as universidades tecnológicas estão orientadas primordialmente a jovens que "provêm de uma origem social mais modesta que no restante do ensino superior $^{30 "}$ e estão localizados em regiões distantes do território nacional que,

29 Nota da tradutora - Traduzido a partir da citação original utilizada pelo autor: "debe existir no importando qué tan bien funcione un sistema económico".

30 Nota da tradutora - Traduzido a partir da citação original utilizada pelo autor: "provienen de un origen social más modesto que el resto de la enseñanza superior". 
comumente, carecem de serviços educativos; nesse sentido, com sua criação se buscava "democratizar o ensino superior" (PAIR apud CGUT, 2000, p. 7).

Outro aspecto relevante dos modelos educativos das universidades tecnológicas é que seus cursos acadêmicos são de curta duração (dois anos ou três mil horas) e de tipo profissionalizante ${ }^{31}$, já que os jovens que vivem nas áreas em que se encontram essas instituições não podem permanecer na escola por períodos longos porque carecem de recursos econômicos. Por isso o governo mexicano desenvolveu uma modalidade acadêmica que ofereceria carreiras curtas e com enfoque profissionalizante que permitiria aos jovens dos grupos relativamente desfavorecidos ingressar no mercado de trabalho de modo mais rápido e fácil (SEP, 1991a; RESÉNDIZ, 1998). Outras justificativas usadas pelo governo para a criação das UTS se baseiam em raciocínios de tipo econômico-funcional e administrativo-redistributivo, que já foram revisados criticamente em outro momento (FLORES-CRESPO, 2002a).

A condição de desvantagem socioeconômica de que, segundo o governo mexicano, padecem os possíveis usuários dessas instituições é um bom ponto de partida para analisar a relação entre educação e desigualdades. Pode a educação profissionalizante reduzir a desigualdade? Uma vez que os jovens cursam uma carreira na UTN estão mais capacitados $^{32}$ para superar as dificuldades sociais e econômicas de que padecem em seu entorno? Até que ponto a educação da universidade tecnológica pode diminuir a desigualdade de capacidades? Para responder a essas perguntas, foi necessário coletar informações dos próprios egressos da Universidade Tecnológica de Nezahualcóyotl. Para cumprir com esse requisito, empregaram-se dois instrumentos para a coleta de informações: um questionário e uma entrevista semiestruturada.

\section{Os métodos de coleta de informação}

O questionário incluiu 22 perguntas fechadas com o objetivo de obter informação estrutura sobre o nível socioeconômico dos egressos. Foi aplicado

31 Meu argumento para dizer que os modelos educativos das universidades tecnológicas são profissionalizantes ou vocacionais, se baseia em que o vocationalism somente se define como uma filosofia ou pedagogia educativa que propõe que o plano de estudos deve se reger por um enfoque ocupacional ou de utilidade para a indústria (DICIONÁRIO OXFORD DE SOCIOLOGIA, 1998). Por outra parte, Winch e Gingell (1999) dizem que a educação vocacional é uma forma de instrução acadêmica com fins primordialmente instrumentais. Como pode se observar, essas definições não são exclusivas para determinado estágio educativo, sendo que o termo vocacional pode ser usado, sem problemas, no caso da educação superior.

32 Estar "capacitado", nesse artigo, se refere à aquisição de capacidades humanas. Portanto, esse termo implica uma conotação mais ampla que a que comumente se conhece e que deriva do processo de instrução chamado capacitação. 
a 451 egressos da citada instituição durante uma reunião organizada ex profeso, à qual foram convocados todos os egressos da instituição no mês de agosto de $2000(3,579)$. Ainda que esse trabalho não pretenda fazer generalizações ${ }^{33}$, é preciso assinalar que a mostra de egressos representou $12,6 \%$ da população total. Esse subconjunto foi dividido equitativamente entre homens e mulheres. Mais além $73 \%$ dos jovens que responderam ao questionário eram solteiros, $23 \%$ estavam casados e $4 \%$ não declararam seu estado civil. A média de idade dos respondentes foi de 23 anos.

Quanto à proporção de egressos de cada carreira e geração da amostra, pode-se afirmar que essa, na maioria dos casos, guardou relação com aquela da população (Tabelas 1 e 2).

TABELA 1 - PROPORÇÃO DE EGRESSOS RESPONDENTES POR CARREIRA

\begin{tabular}{|c|c|c|c|}
\hline & & Muestra \% & Población \%* \\
\hline Procesos de producción & & 12.2 & 11 \\
\hline Comercialización & & 17.7 & 25 \\
\hline Informática & & 35.3 & 22 \\
\hline Administración & & 21.5 & 33 \\
\hline Tecnología ambiental & & 5.3 & 5 \\
\hline Telemática & & 7.1 & 4 \\
\hline Sin respuesta & & 0.9 & - \\
\hline & Total & 100 & 100 \\
\hline
\end{tabular}

FONTE: Departamento de egressos da UTN, 2001.

TABELA 2 - PROPORÇÃO DE EGRESSOS RESPONDENTES POR GERAÇÃO

\begin{tabular}{|c|c|c|}
\hline Año de finalización de estudios & Muestra \% & Población \% ${ }^{*}$ \\
\hline 1993 & 5 & 4 \\
\hline 1994 & 4 & 11 \\
\hline 1995 & 5 & 10 \\
\hline 1996 & 9 & 12 \\
\hline 1991 & 12 & 17 \\
\hline 1998 & 25 & 18 \\
\hline 1999 & 28 & 22 \\
\hline 2000 & 6 & 6 \\
\hline Sin respuesta & 6 & - \\
\hline Total & 100 & 100 \\
\hline
\end{tabular}

FONTE: Departamento de egressos da UTN, 2001.

33 Como já foi dito, esse artigo é parte de uma tese doutoral sobre educação e desenvolvimento, na qual se adotou um enfoque explicativo em lugar de um de tipo descritivo. (FLORES-CRESPO, 2002b). 
Cabe destacar que a informação quantitativa é somente uma base primária para conhecer as condições socioeconômicas, trabalhistas e educacionais dos egressos já que é difícil, através de um questionário, identificar as realizações dos egressos e sua liberdade para alcançá-las, sendo preciso completar a informação estruturada com dados de tipo qualitativo. Para isso, desenhou-se uma amostra não probabilística de Técnicos Superior Universitários (TSU) com o propósito de dirigir uma entrevista personalizada. Para selecionar essa amostra foram considerados dois critérios: 1) sua situação laboral (empregado ou desempregado) e 2) no caso de estar ocupado, seu nível salarial que poderia ser alto, médio ou baixo, de acordo com o número de salários mínimos recebidos. No total, foram entrevistados 26 egressos, dos quais 23 estavam empregados e três buscavam emprego ou seguiam estudando. Dos egressos que trabalhavam, sete recebiam salários entre sete e mais de nove salários mínimos ("alto”), enquanto onze técnicos tinham uma renda entre três e sete salários mínimos ("médio"), e cinco, de menos de um salário mínimo até três ("baixo").

Como dito anteriormente, a informação quantitativa e a qualitativa obtidas serviram para avaliar as realizações e as capacidades dos indivíduos que estudaram na UTN. Nesse caso, referimo-nos a três realizações ${ }^{34}$ ligadas tanto a algum tipo de melhora pessoal como às realizações do tipo profissional. Especificamente, essas realizações são que o egresso seja capaz de: 1) sentir confiança, uma vez que estudou em uma instituição tecnológica de ensino superior; 2) adquirir habilidades adicionais e as valorizar e 3) desempenhar um trabalho como resultado do conhecimento técnico adquirido.

Antes de apresentar os resultados dessa avaliação, convém dar a conhecer brevemente o contexto social em que vivem e operam os jovens que desejam ir à universidade tecnológica a fim de compreender a relação entre desigualdade e educação superior.

\section{Cidade de Nezahualcóyotl: seu passado e sua universidade}

O processo de formação social, econômica, política e cultural de Nezahualcóyotl merece a atenção dos investigadores sociais, se levarmos em conta

34 Outras realizações se apresentam em minha tese de doutoramento (FLORES-CRESPO, 2002b), onde também sublinho a carência desse tipo de indicadores para a educação universitária, por isso a necessidade de um maior trabalho empírico nesse sentido. Existem alguns outros functionings que foram desenvolvidos para grupos específicos como o das mulheres e que podem resultar úteis na definição das realizações (NUSSBAUM, 1995). 
que esse município recebeu constantemente "o juízo sumaríssimo 35 ", sendo estereotipado como um "povoado marginalizado", segundo Martínez (1986, p. 26). E assim Nezahualcóyotl, dizia um ex-governador do estado, se assentou "sobre um bloco enorme de migalhas de pão com sal", portanto, "era de se supor que nada se poderia construir em cima" e nem "os seres mais heroicos e sem escrúpulos das escalas vegetal e animal ${ }^{36 "}$ " poderiam viver ali, dizia Hank Gonzales (apud ALVARADO, 1992, p. 154). Porém, surpreendentemente, “a planície solitária se povoou de uma humanidade abundante que se indignava com todas as exigências que tem direito de impor o homem ${ }^{37}$ " (ALVARADO, 1992, p. 154). Uma dessas exigências, seguramente foi a educação, de que decorra se afirmar que "com o fim de atender a uma antiga demanda dos povoadores do município de Nezahualcóyotl" se tenha criado a universidade tecnológica que, segundo outro governador, poderia ser "o eixo de um programa dirigido a transformar a fisionomia econômica e social do município 38 " (apud CGUT, 2000, p. 195-196).

A cidade de Nezahualcóyotl está localizada na parte oriente do estado do México e concentra uma população de mais de um milhão e duzentos mil habitantes (INEGI, 1999), da qual somente 19\% cursava algum nível educativo. O sistema educacional de Neza aglutinava pouco mais de 200 mil crianças e jovens (INEGI, 1999); o mais interessante, é que, dessa cifra, 90\% cursavam algum grau de educação básica quando em todo o estado essa proporção era significativamente menos (53\%) (SEP, 1999). Mais além uma cifra muito baixa de jovens (8\%) cursava educação média superior (INEGI, 1999), sendo possível dizer que a educação formal não era uma característica que os habitantes ou cronista de Neza poderiam orgulhosamente mostrar. De fato, em 1991, a Secretaria de Educação Pública previa que, ante a carência de instituições de nível superior de tipo público nesse município, a afluência de jovens de cursos preparatórios para a recém-criada Universidade Tecnológica Nezahualcóyotl ia ser alta (SEP, 1991b). Ainda que os cálculos de matrícula feitos nesse momento fossem demasiado otimistas, é inegável que a UTN tem registrado um incre-

35 Nota da tradutora - Traduzido a partir das citações originais utilizadas pelo autor: "el juicio sumaríssimo" e "pueblo marginado".

36 Nota da tradutora - Traduzido a partir das citações originais utilizadas pelo autor: "sobre un enorme bloque de migajón con sal" e "era de suponerse que nada se podría construir encima. ni los más heroicos y desaprensivos seres de las escalas vegetal y animal"

37 Nota da tradutora - Traduzido a partir da citação original utilizada pelo autor: "el páramo se pobló de una abundante humanidad que se encrespaba con todas las exigencias que tiene derecho a imponer el hombre".

38 Nota da tradutora - Traduzido a partir das citações originais utilizadas pelo autor: "con el fin de atender una antigua demanda de los pobladores del municipio de Nezahualcóyotl" e "el eje de un programa dirigido a transformar la fisonomía económica y social del município". 
mento constante no número de estudantes desde sua fundação, o que corrobora o acerto de ser criada uma universidade nessa antiga "planície solitária". De acordo com a CGUT (2002), a UTN provê educação a 2,807 jovens em alguma de suas seis carreiras, e essa cifra a converte na universidade tecnológica com maior número de alunos no país.

Apesar de Nezahualcóyotl ter sido povoada por indivíduos que vinham fugindo da "miséria campesina" ou da "miserável realidade da capital das miragens ${ }^{39 "}$ " (MARTÍNEZ, 1986), é inegável que gradualmente surgiram oportunidades para que a população melhorasse sua qualidade de vida e, nesse processo, a educação tem desempenhado um papel primordial. Por isso a importância de estudar a desigualdade tomando como caso de estudo os egressos da UTN.

\section{A educação superior pode diminuir a desigualdade?}

O México, em comparação com outros países latino-americanos de crescimento econômico similar, tem uma baixa proporção de estudantes cursando a educação superior. Segundo o Observatório Cidadão da Educação (OCE, 2000a), para o período 2000-2001, enquanto o Chile apresentava uma taxa de cobertura de $28 \%$, o México alcançava $20 \%$; ou seja, de cada dez mexicanos com idade para entrar na universidade, somente dois conseguiam fazê-lo. O grande desafio está em "ampliar e diversificar as oportunidades de acesso à educação superior e aproximar a oferta educativa dos grupos sociais em situação de desvantagem [...]" (SEP, 2000b, p. 189). É por essa razão que se seguem criando universidades tecnológicas em zonas relativamente pobres do país. Apesar do inegável esforço para expandir a educação superior mexicana, há também de se investigar até que ponto a provisão de educação serve para reduzir a desigualdade de capacidade.

\section{Razões para estudar na Universidade Tecnológica de Nezahualcóyotl}

Como já foi dito, a matrícula da UTN tem registrado um número crescente de alunos e, portanto, de egressos desde sua fundação. Porém, não foram men-

39 Nota da tradutora - Traduzido a partir das citações originais utilizadas pelo autor: "miseria pueblerina" e "miserable realidad de lacapital de los espejismos". 
cionadas as causas pelas quais os titulados escolheram essa instituição como uma opção educacional. A Tabela 3 apresenta algumas das razões para escolhê-la e dá pistas para conhecer a desigualdade de que padecem os indivíduos dessa região.

\section{TABELA 3 - RAZÕES PARA ESCOLHERA UT DE NEZAHUALCÓYOTL COMO OPÇÃO EDUCACIONAL}

\begin{tabular}{lrr}
\hline & Abs \% & \% \\
\hline a. Debido a la conveniencia de sus cursos cortos & 137 & 31 \\
b. Porque necesitaba conseguir un trabajo rápidamente & 12 & 2 \\
c. Porque no fui aceptado en la UNAM_Poli_UAM_Otra_- & 152 & 34 \\
d. Porque quería adquirir mayores conocimientos & 81 & 18 \\
e. No lo sé & 4 & 1 \\
f. Otra & 47 & 10 \\
g. Sin respuesta & 18 & 4 \\
\hline \multicolumn{1}{c}{$\quad$ Total } & 451 & 100 \\
\hline
\end{tabular}

FONTE: Departamento de egressos da UTN, 2001.

Como se observa, para a maioria dos egressos (34\%), a UTN foi a segunda opção para estudarem já que não haviam sido aceitos nas principais universidades públicas da Cidade do México ${ }^{40}$.

Vale recordar que o ingresso a essas instituições de educação superior requer a certificação de um exame que avalia o conhecimento que o aspirante deve ter, independentemente de sua sorte, nível socioeconômico, cultura, raça, sexo, linguagem, religião ou deficiência física (UNESCO, 2000). Se forem levadas em conta as marcadas desvantagens educativas, sociais e econômicas que enfrentam algumas localidades mexicanas, torna-se inegável que uma quantidade considerável de indivíduos se beneficiou da oportunidade de estudar na UTN. Esse é, sem dúvida, um assunto que em outra ocasião deve ser abordado, já que pode levar a interessantes debates acadêmicos sobre a relação entre o mérito dos indivíduos, as oportunidades educativas existentes e a igualdade de capacidades $^{41}$.

É difícil saber com precisão o que teria acontecido com aqueles jovens que não foram aceitos na Universidade Nacional Autónoma do México

40 Como é sabido, a UNAM conta com instalações universitárias em várias regiões, incluindo as do estado do México.

41 Algumas leituras úteis nesse sentido poderiam ser o artigo de Philip Collins intitulado "A Story of Justice", publicado na revista inglesa Prospect, em maio de 2001, ou o trabalho de Goldthorpe (1997). Outra fonte de análise crítica são os comunicados do Observatorio Ciudadano de la Educación. Ver, especificamente, OCE (2000b). 
(UNAM), no Instituto Politécnico Nacional (IPN) ou na Universidade Autônoma Metropolitana (UAM), se não tivesse sido aberta a Universidade Tecnológica de Nezahualcóyotl. Acaso ocorreria uma perda mais acentuada de realizações e de capacidades humanas? O que é certo dizer é que a UTN reduziu de maneira significativa a exclusão social. Isso mostra a importância de haver um espaço de conhecimento em regiões relativamente pobres onde os seres humanos podem socializar, aprender e desenvolver-se a nível pessoal, entre diversas outras coisas.

Além disso, a Tabela 3 mostra que a proporção de aspirantes que selecionaram a UTN pela "conveniência de seus baixos cursos" é quase igual à dos jovens que a escolheram como segunda opção (31\% e 34\%, respectivamente). Dessa forma, o governo mexicano cumpriu com a expectativa de oferecer carreiras de curta duração a grupos em relativa desvantagem socioeconômica com o objetivo de reduzir os custos de oportunidade de ir à escola. Um dos egressos do programa de Técnico Superior Universitário em Administração, entrevistado para o presente estudo, de 29 anos, comentou ter selecionado a instituição por diversos fatores como o econômico e a distância:

Estive trabalhando em Nezahualcóyotl e, pouco depois de ter sido aberta a universidade, me informei sobre como estava, gostei de seu sistema, gostei do nivel de ensino que trazia e, bem, ingressei. De fato, antes estudei três anos engenharia elétrica no Politécnico e por questões econômicas tive que abandonar e, bem, depois se apresentou a oportunidade de ingressar na $U T N^{42}$.

Mesmo quando esse jovem cumpriu com os requisitos de ingresso em outra instituição de educação superior (ser aprovado em exames de ingresso, pagar a mensalidade etc.), ele deixou de estudar devido às limitações econômicas. Porém, a opção da Universidade Tecnológica de Nezahualcóyotl lhe permitiu retornar aos estudos e, assim, adquirir conhecimento, agora se encontra trabalhando no setor moderno da economia mexicana. Seu salário mensal era de nove mil pesos mexicanos e, durante a entrevista, comentou que a educação que lhe proporcionou a UTN lhe deu bases para "desenvolver-se" no campo laboral e "seguir se preparando".

42 Nota da tradutora - Traduzido a partir da citação original utilizada pelo autor: "Estuve trabajando en Nezahualcóyotl y tenía poco de haberse abierto la universidad, me informe cómo estaba, me gustó su sistema, me gustó el nivel de enseñanza que traía y bueno, ingresé. De hecho antes estudié tres años en el Politécnico ingeniería eléctrica y por cuestiones económicas tuve que abandonarla y, bueno, después se presentó la oportunidad de ingresar a la UTN". 


\section{O nível de emprego e de renda: colocando o dinheiro em seu lugar}

Pablo Latapí (1997, p. 17) argumenta que o emprego é uma meta "natural e horizonte sempre presente na educação ${ }^{43}$ ", porém, em tempos de crise econômica e restrições trabalhistas, algumas universidades, tanto públicas como privadas, veem o emprego como uma meta única e essencial, mais que natural. Já se argumentou em outra ocasião que promover a ideia de que a educação deve responder somente aos requerimentos do mercado de trabalho poderia nos levar a um reducionismo com respeito a seus efeitos sobre os seres humanos (FLORES-CRESPO, 2002a, 2002b). Aqueles que vão à universidade aspiram a desempenhar diversos papéis na vida, além de estarem empregados ou receberem um salário com o simples propósito de acumulação econômica. $\mathrm{O}$ dinheiro pode ser somente um meio para expandir suas realizações e, portanto, suas capacidades. Nesse sentido, Amartya Sen afirma que não seria estranho que - se uma pessoa melhora seu nível educacional e, consequentemente, é mais frutífera na produção de bens - também tenha mais possibilidades "e liberdade" para dirigir sua vida: "É importante ver aos seres humanos de uma perspectiva mais ampla ${ }^{44 "}$ (SEN, 1999, p. 294-296).

O fato de uma pessoa adquirir conhecimentos é um passo para a redução de sua desigualdade. Porém ir à escola ou à universidade é um processo que se concatena com diversas experiências que contribuem para melhorar a qualidade de vida do ser humano. Uma dessas experiências, sem dúvida, é o emprego, pois permite ao indivíduo operar suas habilidades práticas e intelectuais de maneira que, ao melhorar um processo produtivo, seu esforço possa ser retribuído em termos pessoais e econômicos. Caso contrário, se uma pessoa está desempregada, isso não afeta apenas sua renda, mas também lesiona sua saúde física e mental e a coloca em risco de exclusão social (SEN, 1999).

O estudo realizado mostra que de cada dez técnicos superiores universitários, oito contavam com um emprego formal, enquanto os dois restantes estavam em busca de uma posição laboral ou estudando. Ainda assim se detectou que, à medida que o tempo passa, menos egressos têm problemas para conseguir trabalho; $40 \%$ do total de respondentes se incorporaram ao setor produtivo em menos de um mês e apenas $7 \%$ deles levaram entre seis meses e um ano para fazê-lo. Com base nesses resultados, pode-se inferir que os jovens que vão

43 Nota da tradutora - Traduzido a partir da citação original utilizada pelo autor: "natural y horizonte siempre presente en la educación".

44 Nota da tradutora - Traduzido a partir da citação original utilizada pelo autor: "Es importante ver a los seres humanos en una perspectiva más amplia” 
a essa universidade estão imersos em um processo contínuo de aquisição e transformação de realizações e que, portanto, podem reduzir sua desigualdade em comparação com aquelas pessoas que não têm a oportunidade de adquirir conhecimentos e de se ocupar. Analisemos, agora, o nível de renda como meio para obtenção de maiores capacidades.

O gráfico 1 mostra uma linha contínua que representa o percentual de técnicos superiores universitários de acordo com seu nível salarial em seu primeiro trabalho, enquanto a linha descontínua representa a proporção de jovens em relação à sua renda por produto de trabalho em seu emprego atual. Cada corte inclui uma faixa salarial específica. O I concentra a percepção monetária mais baixa, e o VI registra a renda por produto de trabalho mais alta.

\section{GRÁFICO 1 -PERCENTUAL DE EGRESSOS POR NÍVEL SALARIAL INICIAL E ATUAL}

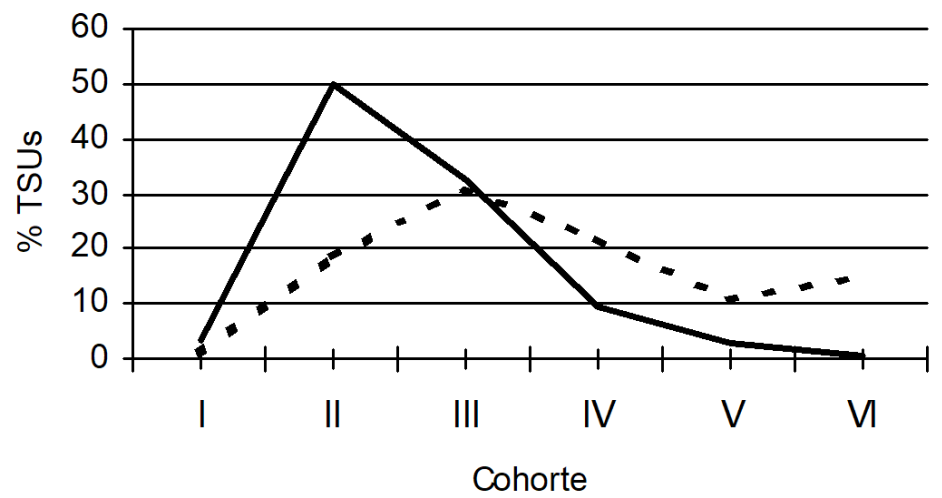

\section{Salario inicial - - - - Salario actual}

FONTE: Departamento de egressos da UTN, 2001.

Como se observa, o corte II concentra a mais alta proporção de egressos, isso quer dizer que, quando começaram sua vida laboral, a maioria dos técnicos superiores universitários ganhava entre um e três salários mínimos mensais. É evidente que muito poucos receberam salários altos em seus primeiros empregos, visto que as proporções de titulados dos cortes que registram os salários mais altos (IV, V e VI) diminuem de maneira significativa ( $9 \%, 2 \%$ e $8 \%$, respectivamente). À medida que esses egressos completaram mais em seu emprego, como mostra a linha pontilhada, observa-se que o corte III aglutina a proporção maior, e a maioria ganha salários mais altos do que quando começaram sua carreira 
profissional. É interessante ressaltar que a proporção de jovens nos cortes IV, V e VI aumentou substancialmente com o tempo $(22 \%, 11 \%$ e $15 \%$, respectivamente). O "salto" que se observa, na proporção de titulados do corte $\mathrm{V}$ aos de renda VI, merece uma maior atenção. Esse aumento se explica porque, com o passar do tempo, dentro de um determinado emprego, esses técnicos superiores universitários adquirem experiências laborais, relações pessoais, maiores habilidades e demais realizações, estando mais capacitados para buscar melhores oportunidades laborais e, consequentemente, aumentar sua renda.

Portanto, ao obter maiores capacidades, os egressos da universidade tecnológica podem, entre outras coisas, incrementar seu salário. Com maior renda, maiores realizações. Isso é amplamente reconhecido por Amartya Sen em sua obra Desenvolvimento como Liberdade, em que diz: "temos razões excelentes para querer possuir mais renda ou riqueza, e não é porque renda ou riqueza sejam desejáveis em si mesmas, senão porque, por norma, são importantes meios de uso geral para se ter mais liberdade para levar o tipo de vida que temos razão em valorizar ${ }^{45}$ " (SEN, 1999, p. 14).

O raciocínio de Sen sobre a renda ou a riqueza econômica reforça a ideia de que os bens materiais servem para alcançar maior liberdade, ou seja, são meios para alcançar o bem-estar e não seus fins. No entanto, buscar um emprego que provenha melhores rendas para as pessoas leva, em muitos casos, a um movimento migratório. Apesar do negativo que pode ser para a região, a migração de jovens preparados - deixar um lugar por outro, em busca de melhores oportunidades - reflete também uma capacidade que se pode explicar por diversas razões, tais como: segurança e iniciativa do migrante, suas relações familiares em outros lugares, sua idade - um menino que necessita de dinheiro, dificilmente se moverá de uma região a outra sem correr perigo - e, por que não, seu nível de conhecimento prático e teórico que pode aplicar onde quer que escolha.

Esse estudo corroborou para que os egressos, especificamente aqueles com salários altos, que emigraram de Neza para trabalhar na Cidade do México e em diversos pontos do estado do México, já que Nezahualcóyotl não lhes fornecia condições econômicas suficientes. A respeito disso, um dos técnicos profissionais universitários da área da administração argumentava que: "há muitas microempresas, há fontes de trabalho, sim, desgraçadamente não existem as expectativas econômicas que permitam ter uma vida aceitável, porque o salário que oferece

45 Nota da tradutora - Traduzido a partir da citação original utilizada pelo autor: "tenemos excelentes razones para querer poseer más ingreso o más riqueza, y no es porque el ingreso y la riqueza sean deseables en sí mismas, sino porque, por norma, son importantes medios de uso general para tener más libertad con la que poder llevar el tipo de vida que tenemos razón de valorar”. 
esse tipo de negócio é o mínimo ${ }^{46 "}$. Esse fato foi sustentado por uma egressa de comercialização que estava desempregada e, apesar de reconhecer a existência de certo tipo de empregos em Neza, percebia que:

Egressa: Nezahualcóyotl vai crescendo pouco a pouco, não tem muito que foi formado e são miniempresas as que estão se formando. Há muito poucas oportunidades aqui, dentro de Nezahualcóyotl, a menos que você saiba de política ou tenha algo que ver com a política, nesse âmbito sim pode-se entrar para trabalhar.

Pesquisador: Não acredita que os TSU tenham espaço nessas miniempresas?

Egressa: Sim, podem ter [...] a maioria dessas empresas são importadoras que não tem registro na [Secretaria de] Fazenda e, portanto, estão trabalhando em um lugar fechando que lhes é vendido por empresas grandes do Distrito Federal [...] são importadoras de mochilas, roupa, sapatos, cintos, móveis.

Pesquisador: Você foi buscar trabalho ai?

Egressa: Não, eu não gosto por experiências de que fiquei sabendo, com pessoas muito próximas a mim. Em primeiro lugar, o salário é baixo, menos que o mínimo. Ai trabalham por peça, de acordo com o que eles [os trabalhadores] realizem, assim se paga a eles, cem, duzentos ou até mil unidades vão fazendo e também não tem seguro, não podem faltar nenhum dia; se faltam, ou são despedidos ou perdem a metade do salário. Esses são os problemas. ${ }^{47}$

46 Nota da tradutora - Traduzido a partir da citação original utilizada pelo autor: "hay muchas microempresas, hay fuentes de trabajo, sí, desgraciadamente no existen las expectativas económicas que permitan tener una vida aceptable porque el sueldo que ofrecen este tipo de negocios es el mínimo".

47 Nota da tradutora - Traduzido a partir da citação original utilizada pelo autor: "Nezahualcóyotl va creciendo poco a poco, no tiene mucho que se formó y son miniempresas las que se están formando. Hay muy pocas oportunidades aquí, dentro de Nezahualcóyolt, a menos de que tú sepas de política o tengas algo que ver con la política, en esse ámbito sí puedes entrar a trabajar. Investigador: ¿No crees que los TSU tienen cabida en esas miniempresas? Egresada: Sí, sí pueden tener [.] la mayoría de estas empresas son maquilas que no tienen registro en [la Secretaría de] Hacienda y pues están trabajando en un lugar cerrado las cuales les venden a empresas grandes del DF [.] son maquilas de mochilas, ropa, zapatos, cinturones, muebles. Investigador: ¿Has ido a buscar trabajo ahí? Egresada: No, no me gusta por experiencias de que he sabido de personas muy cercanas a mí. En primera, el salario es bajo, menos del mínimo. Ahí trabajan por destajo, de acuerdo 
Não havendo facilidades econômicas para os egressos da UTN, não é estranho supor que tendam a emigrar em busca de melhores oportunidades. Nessas condições, é difícil pensar que um modelo curricular, como o das universidades tecnológicas, favoreça, como pretende a Secretaria de Educação Pública (2000, p. 68), "a permanência dos jovens em seu lugar de origem ${ }^{48 "}$. Reconhecer que uma pessoa que adquire conhecimento pode atuar de uma forma ou de outra com o propósito de mobilizar-se em busca de seu próprio bem-estar é um passo necessário para entender as desigualdades dentro do campo educacional. Claro, isso não invalida que também se reconheça que a migração de profissionais seja um fenômeno regressivo para o país ${ }^{49}$. Entretanto, a solução para a "fuga de cérebros" aponta para outro tipo de políticas públicas e não apenas as políticas educacionais.

Ter a capacidade de emigrar de uma área a outra em busca de melhores oportunidades, assim como não aceitar trabalhos cujas condições prejudiquem - mas que favoreçam - as realizações dos indivíduos, é um fato que até certo ponto mostra a liberdade de alunos egressos da Universidade Tecnológica de Nezahualcóyotl para dirigir suas vidas como desejarem. Pensar que "não há saída" da pobreza é uma ideia questionável se for colocada maior atenção na ação das pessoas que adquirem conhecimento. Cedo ou tarde, diz Mantzavinos (2001, p. 3), "cada análise da sociedade e da economia deve usar as explicações a partir do que fazem os indivíduos ${ }^{50}$ ". Exemplo disso é a opinião de uma egressa (28 anos) da carreira de Técnico Superior Universitário em Informática da instituição que nos ocupa:

Se não tivesse estudado, continuaria no mesmo círculo social e dificilmente teria saido [...]. Ao sentir-me com armas, com ferramentas, isso me deu coragem de sair desse círculo e, sabe o quê? Vá buscar outro lugar, outras pessoas, outro trabalho, outro ambiente. Eu acredito que a Universidade sim me deu demasiados beneficios ${ }^{51}$.

con lo que ellos [los trabajadores] realicen así se les paga, cien, doscientas o hasta mil unidades van haciendo y también no tienen seguro, no pueden faltar ningún día; si faltan, o los corren o les quitan la mitad del sueldo. Esos son los problemas.

48 Nota da tradutora - Traduzido a partir da citação original utilizada pelo autor: "la permanencia de los jóvenes en su lugar de origen".

49 No México, parece haver uma relação positiva entre o nível socioeconômico dos estados mais desfavorecidos com a perda de profissionais através da migração. Segundo o INEGI (1993), os entes com maior perda de profissionais eram Zacatecas, Oaxaca, Hidalgo e Guerrero, enquanto que os que mais ganhavam era Quintana Roo, México, Querétaro e Baja California Sur.

50 Nota da tradutora - Traduzido a partir da citação original utilizada pelo autor: "cada análisis de la sociedad y la economía debe usar las explicaciones de lo que hacen los indivíduos".

51 Nota da tradutora - Traduzido a partir da citação original utilizada pelo autor: "si no hubiera estudiado, continuar ía en el mismo círculo social y difícilmente hubiera salido [...] Al 


\section{Os efeitos da educação dentro de uma visão humanista}

A ideia de que a universidade tecnológica é uma instituição que deve contribuir para o crescimento econômico da região se sustenta em um conceito funcional que considera o capital humano como detonador do avance produtivo. Apesar da utilidade da teoria do capital humano - e de algumas evidências -, esse enfoque, precisa Amartya Sen, necessita ser complementado já que "os seres humanos não são meros meios de produção, senão que também a finalidade desse exercício ${ }^{52 "}$ "(SEN, 1999, p. 295-296). Por isso o Nobel da Economia sugere nos centrarmos não somente no papel indireto que desempenham as capacidades humanas - alcançadas mediante a educação ou a capacitação - na produção econômica e na mudança social, senão na "importância direta para o bem-estar e a liberdade dos indivíduos ${ }^{53}$ " (SEN, 1999, p. 296, grifos do autor). Essa visão humanista do professor hindu é congruente, e motiva-nos a deixar de pensar somente nas características ideais do capital humano útil para o progresso econômico ${ }^{54}$. Pablo Latapí questionou o termo capital humano em um artigo sobre Paulo Freire, em que diz que a pedagogia libertadora poderia afirmar o valor do homem consciente e crítico, ao invés de recurso humano instrumental e subordinado. Essa prática educativa, segundo o educador mexicano, cujo pensamento também dialoga com o de Amartya Sen, poderia dar lugar a que a “economia esteja a serviço das necessidades humanas ${ }^{55 "}$ (LATAPÍ, 1998, p. 101).

Uma vez que a educação tem efeitos mais além da escala macroeconômica e que deve buscar o bem-estar das pessoas, é necessário indagar que benefícios

sentirme con armas, con herramientas, pues me dio valor a salir de ese círculo y, ¿sabes qué? vete a buscar a otro lado, otra gente, otro trabajo, otro ambiente, yo creo que la Universidad sí me dio demasiados benefícios".

52 Nota da tradutora - Traduzido a partir da citação original utilizada pelo autor: "los seres humanos no son meros medios de producción sino también el fin de este ejercicio".

53 Nota da tradutora - Traduzido a partir da citação original utilizada pelo autor: "la importancia directa para el bienestar y la libertad de los indivíduos".

54 De modo congruente com essas ideias, se deveria deixar de pensar que no processo de recrutamento e seleção de pessoal, as pessoas "devem vender-se melhor", pois graças a sua noção de pessoa não podem ser tratados como produtos. Ainda assim, é pouco sério dizer que o processo de certificação profissional - que está sendo empreendido na educação superior no México - é passo para colocar "o selo de qualidade" nas pessoas, já que se deve considerá-las como seres "únicos e irrepetíveis" (usando os termos de Octavio Paz, 1993), não como objetos produzidos sob algum tipo de padrão. Essas aclarações aparentemente simples e irrelevantes podem ter importantes implicações de fundo.

55 Nota da tradutora - Traduzido a partir da citação original utilizada pelo autor: "economía esté al servicio de las necesidades humanas". 
obtiveram os egressos depois de terem estudado uma carreira técnica na Universidade Tecnológica de Nezahualcóyotl. O gráfico 2 mostra que esse espaço acadêmico cumpriu a missão de proporcionar a maioria dos jovens (41\%) conhecimentos inovadores para aplicar no mercado de trabalho.

\section{GRÁFICO 2 - OS BENEFÍCIOS DE HAVER ESTUDADO NA UT DE NEZAHUAL- CÓYOTL}
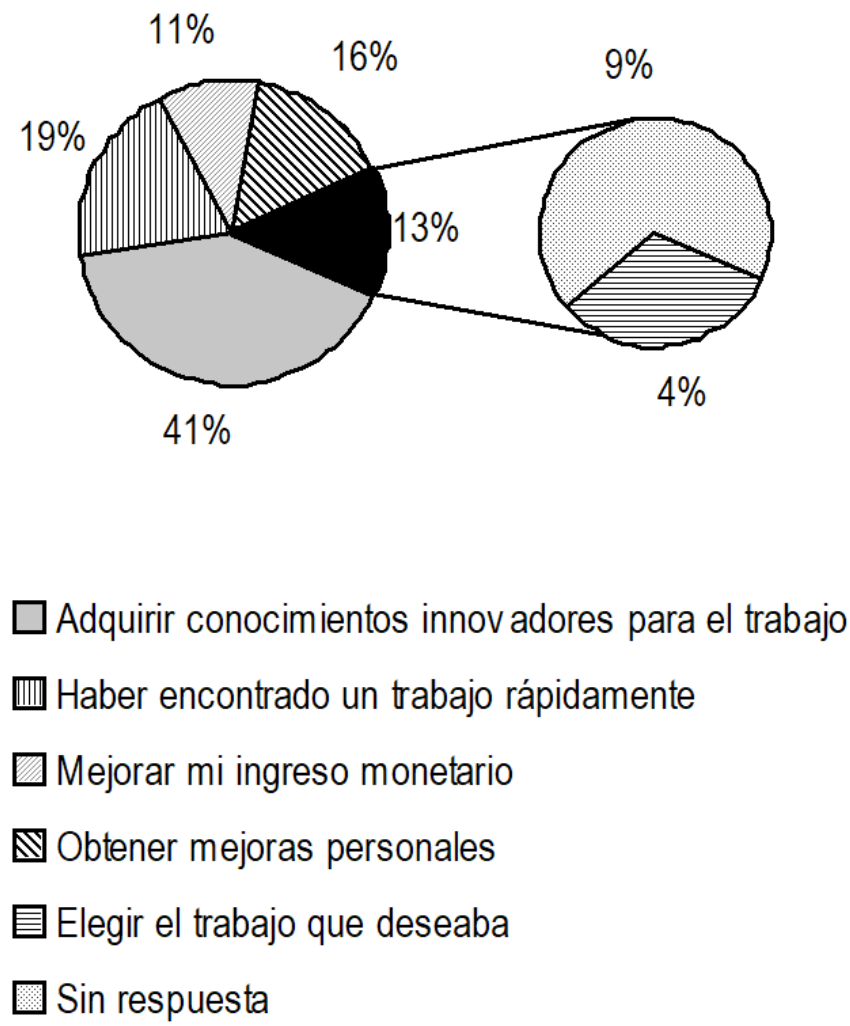

FONTE: Departamento de egressos da UTN, 2001.

O presente estudo demonstra que os egressos da UTN, independente de sua renda, carreira, idade ou sexo, além de obter conhecimentos práticos, alcançaram retribuições pessoais e puderam se incorporar ao setor laboral em curto prazo (16\% e 19\%, respectivamente). Pode-se afirmar que com a criação dessa universidade, os jovens desse município do estado do México tiveram 
acesso a outras oportunidades sociais que lhes permitiram viver melhor (usando as palavras de Sen). Uma egressa de 22 anos, da carreira de técnico superior universitário, cuja renda é de dois mil e quinhentos pesos mexicanos disse:

Me deixava triste estar falando com as pessoas, me relacionar com elas; coisas que na universidade foram mudando com apresentações, com as diferentes tarefas que nos davam, no relacionamento com as empresas. Nisso me fizeram mudar a mim mesma. Agora meu trabalho é basicamente tratar com pessoas e isso já não me deixa triste, ao falar, e antes sim, antes de entrar na universidade e nessa carreira ${ }^{56}$.

Esse trabalho revelou que, apesar da maioria dos técnicos superiores universitários contarem com emprego formal e de que a maioria tenha renda entre três e cinco salários mínimos, $90 \%$ dos respondentes (451) queriam estudar uma licenciatura ou uma engenharia. A razão principal era a necessidade de adquirir maiores conhecimentos para aplicá-los no trabalho (na opinião de $45 \%$ dos entrevistados), já que, se fizessem outros estudos, teriam a possibilidade de obter um emprego que lhes brindaria com melhores condições profissionais (30\% da amostra).

Somente $8 \%$ dos respondentes afirmaram que a companhia thes exigia o título de licenciado ou engenheiro para trabalhar, podendo-se supor que a decisão de deixar de ser técnico para se converter em licenciado ou engenheiro era uma aspiração própria dos jovens. Essa pode ser interpretada como em contradição com a ideia de que o México necessitava formar primordialmente pessoas com alguma qualificação de tipo técnico para responder às próximas etapas de nosso desenvolvimento (RESÉNDIZ, 1998). A Organização para a Cooperação e o Desenvolvimento Econômico coincidem com a visão funcionalista de Reséndiz, ao asseverar em seu relatório sobre política educacional no México, que "a efetividade de uma economia moderna depende em um intervalo considerável de seus técnicos e funcionários de nível médio ${ }^{57 \%}$, do que decorre

56 Nota da tradutora - Traduzido a partir da citação original utilizada pelo autor: "A mí me daba pena el estar hablando con las personas, relacionarme con ellas; cosas que en la universidad fueron cambiando con exposiciones, con las diferentes tareas que nos dejaban, el relacionarnos con las empresas. En eso me hicieron cambiar a mí. Ahorita mi trabajo es básicamente tratar con personas y cosa que ya no me da pena, el hablar y antes sí, antes de ingresar a la universidad y a esa carrera".

57 Nota da tradutora - Traduzido a partir da citação original utilizada pelo autor: "la efectividad de una economía moderna depende en un rango considerable de sus técnicos y mandos medios, de ahí que las universidades tecnológicas deberían promoverse como prioridad". 
que as universidades tecnológicas deveriam promover-se "como prioridade" (OCDE, 1997, p. 179 e p. 214).

É estranho que, tanto Reséndiz quanto a citada organização, tenham omitido uma reflexão sobre a racionalidade ou livre-arbítrio das pessoas para atuar de uma forma ou outra, de acordo com suas percepções e aspirações, inclusive deixando de ser técnico superior universitário e decidindo estudar uma licenciatura ou uma engenharia com vistas a melhorar suas condições de vida. Esse aspecto sublinha, por um lado, o fato de que são os jovens que escolhem e traçam suas próprias rotas de desenvolvimento pessoal e, por outro, pode-se dizer que a universidade tecnológica motiva seus estudantes a continuar seus estudos. Isso é relevante se tomarmos em conta a "origem social modesta" dos jovens que vão a essas instituições. Esse achado, a motivação aos estudos universitários, não é observado, de forma geral, em outros países, como, por exemplo, nos Estados Unidos, especificamente no Sul de Los Angeles, Califórnia, onde a população latina e afroamericana padece de severas desvantagens socioeconômicas, os jovens não desejam ir à universidade. Para estimular os jovens de recursos escassos a ingressar no college existe, ex profeso, uma associação civil chamada South Central Youth Empowered through Action que tenta incutir as expectativas por estudos (jornal The Guardian, Inglaterra, 25-08-01). Por isso o fato de que os técnicos superiores desejem continuar seus estudos constitua-se em um aspecto positivo das universidades tecnológicas. Agora, resta corroborar se, em verdade, dão "liberdades instrumentais" para que os jovens adquiram maiores capacidades.

\section{De volta à desigualdade}

Até aqui se argumentou que a Universidade Tecnológica de Nezahualcóyotl representa, em um contexto de sérias desvantagens estruturais, uma oportunidade social para adquirir "realizações" que são o que finalmente forma as capacidades dos indivíduos. Esse fato dificilmente seria realidade sem um espaço educativo, por isso a UTN constitui um passo em direção à redução da desigualdade de capacidades. Como a educação está posta nos indivíduos e não no capital físico (BOWLES, 1977), é lógico pensar que a pessoa que adquire conhecimento buscará estados de bem-estar mais amplos dos que já alcançou. Caso se considere que somente $6 \%$ do total de técnicos superiores universitários respondentes ocupavam um posto de diretor ou gerente ${ }^{58}$, e que os egressos entrevistados se

$58 \mathrm{O}$ resto dos técnicos superiores universitários respondentes trabalham como "assistente administrativo" (23\%); "técnico qualificado" (21\%); "supervisor" (15\%); "operário qualificado" 
queixavam dos baixos salários que recebiam e de alguns trabalhos que eram muito demandantes em questão de tempo, então parece injustificado que nove de cada dez egressos aspirem a estudar uma licenciatura ou uma engenharia.

Uma vez que os egressos conhecem as regras do mercado de trabalho, traçam por si mesmos suas estratégias e atuam em consequência com o propósito de melhorar sua condição pessoal e profissional. Os técnicos superiores universitários pensam que, através de maiores estudos - o que aparentemente se refletem em um título de licenciado ou em um de engenheiro -, lhes será mais fácil ocupar postos de maior hierarquia e assim melhorar suas condições laborais. Interpretar essa aspiração como um simples capricho dos jovens poderia distorcer a análise social e, consequentemente, o desenho de políticas públicas.

$\mathrm{O}$ que aconteceu com todos esses jovens que querem ser licenciados ao invés de técnicos? Foi-lhes dada resposta a sua justificada aspiração? Há possibilidades de que exista, entre esses jovens, a igualdade de capacidades? Segundo a Secretaria de Educação Pública, uma das características do modelo educativo das universidades tecnológicas é a continuidade dos estudos dentro dessas instituições ou em outras do sistema de educação superior: "é justo responder a essa aspiração dos jovens egressos ${ }^{59 "}$ (SEP, 1991a, p. 22). Com base nessas orientações, a Secretaria ofereceu, dentro das instalações da Universidade Tecnológica de Nezahualcóyotl, o chamado "segundo ciclo" a fim de dar a oportunidade aos milhares de egressos de adquirir conhecimento de licenciatura. Isso tinha relevância pois, como foi dito, esse município carecia de opções educacionais públicas de qualidade. Por razões inexplicáveis ${ }^{60}$, até o momento, o segundo ciclo foi cancelado, o que gerou não apenas conflitos políticos $^{61}$, mas também novas desigualdades entre um grupo de pessoas que possuem as mesmas aspirações, cujos níveis econômicos e situações laborais diferem. Um egresso da carreira de informática, de 24 anos, que recebia um salário mensal entre três e cinco salários mínimos, assegurou que estudar uma licenciatura era "difícil” já que não tinha tempo para isso e agregou:

(1\%); "proprietário do seu negócio" $(1 \%)$ e outro posto $(22 \%)$. O restante $(10 \%)$ se concentrou na opção "sem resposta".

59 Nota da tradutora - Traduzido a partir da citação original utilizada pelo autor: "es justo responder a esta aspiración de los jóvenes egresado".

60 A decisão de cancelar o segundo ciclo parece apontar para um conflito de interesses de alguns funcionários da Subsecretaria de Educação e Pesquisa Tecnológica e a Subsecretaria de Educação Superior e Pesquisa Científica.

61 Em 30 de junho de 1999 vários jovens irromperam na oficina do reitor da UTN para exigir que se cumprisse a outorga de títulos de licenciatura oferecidos no segundo ciclo. Ver as notas de Juan Lázaro no periódico El Universal, $1^{\circ}$ de julho e 8 de agosto de 1999. 
Teria que estar trabalhando e estudando [ao mesmo tempo]. Esse trabalho, te digo, é muito absorvente, está muito distante, é muito tempo e, por outro lado, como te digo, aqui por perto [de Neza] não se encontra trabalho facilmente; quando é muito perto, ainda tens que ir ao centro, ao Distrito Federal. A verdade, sim, vejo como um pouco dificil. Sim, eu gostaria, se pudesse encontrar trabalho no governo, aonde trabalhas de 8:00 a 15:00, talvez aventaria ${ }^{62}$.

Como se observa, esse jovem tinha dois impedimentos principais para estudar: o primeiro era a falta de tempo para ir à escola e, o segundo, o custo da oportunidade de estudar. Não podia deixar seu trabalho pela escola. Contrário a essa posição, outro egresso da administração, de 29 anos, cujo salário era de nove mil pesos mexicanos, comentou que, ao não se realizar no segundo ciclo, cursou uma "pós-graduação" na Universidade Tecnológica Americana (UTECA) para obter o grau de licenciatura. Essa instituição privada se encontra na Cidade do México e cobre uma mensalidade dois mil pesos mexicanos, segundo disse outro egresso do técnico superior em informática, de 22 anos. Entretanto, a possibilidade de estudar numa instituição de educação superior pública tampouco era acessível para alguns jovens de Neza. Um egresso do programa de administração da UTN, de 32 anos, comentou que no Instituto Politécnico Nacional (IPN) não teve seus estudos de técnico superior universitário revalidados, tendo que começar desde o primeiro semestre para ter o conhecimento de licenciado. Embora o egresso comente estar agradecido à instituição, também disse estar ressentido com ela porque o título de:

Egresso: Técnico superior universitário te limita demasiado, muitas vezes na rua te veem como se viesse de Conalep ${ }^{63}$ ou alguma escola a nivel médio, não há reconhecimento [...] existe um pouco de rancor, em que você se trunca, as autoridades educativas não nos deram essa opção de poder seguir estudando e poder terminar uma licenciatura.

62 Nota da tradutora - Traduzido a partir da citação original utilizada pelo autor: "Tendría que estar trabajando y estudiando [al mismo tiempo]. Este trabajo, te digo es muy absorbente, está muy lejos, es mucho tiempo y, por otro lado, como te digo, por aquí cerca [de Neza] no encuentras trabajo fácilmente; cuando muy cerca te tienes que ir al centro, al Distrito Federal. La verdad sí lo veo un poco difícil, sí me gustaría, si pudiera encontrar el trabajo en gobierno, donde trabajas de 8 h00 a 15h00, quizá sí me aventaría".

63 Nota da tradutora - Colégio Nacional de Educação Profissional Técnica - instituição de nível médio. 
Pesquisador: Querer estudar uma licenciatura se deve a que necessites maior conhecimento para realizar teu trabalho, te sentes limitado em conhecimento, ou é porque queres estudar?

Egresso: Veja, você sabe perfeitamente que o mundo é grandíssimo; se te disseram que você vai ser capturador de dados e nada mais, tens que aprender o sistema e colocar os dados, bom, pois igualmente ai se acaba o conhecimento. Mas em uma área que é a contabilidade, finanças, o mundo do conhecimento é bastante amplo, não? Então, ainda que tu termines uma carreira, digamos, no Politécnico, como contador público, sempre te estariam fazendo falta atualizações, mais conhecimentos, novas leis, novas teorias, sempre há que se estar pesquisando, o conhecimento é muito amplo ${ }^{64}$.

A citação dessa entrevista confirma a justificada aspiração dos jovens para continuar seus estudos de licenciatura. Como a sociedade não reconhece que se é um técnico superior universitário, optou por estudar uma licenciatura no Politécnico para não se limitar, porque sabe que é necessário atualizar-se continuamente. Mas, de que reconhecimento estaria falando, se foi dito que a maioria dos técnicos egressos da Universidade Tecnológica de Nezahualcóyotl se empregou em um tempo relativamente curto? Do meu ponto de vista particular, é necessário analisar a validade da figura do técnico superior universitário em três dimensões básicas: 1) institucional, 2) laboral e 3) social. A institucional se refere às facilidades burocráticas dentro do sistema de educação superior para revalidar e reconhecer os estudos de técnico superior universitário e o livre-trânsito para qualquer subsistema educativo ${ }^{65}$. Sem dúvida, isso poderia facilitar que inicie sua aprendizagem e, ao longo de sua vida, possa chegar, se

64 Nota da tradutora - Traduzido a partir da citação original utilizada pelo autor: Técnico superior universitario te limita demasiado, muchas veces en la calle te ven como si vinieras de Conalep o alguna escuela a nível bachillerato, no existe el reconocimiento [.] existe un poco rencor en cuanto a que se te trunca, las autoridades educativas no nos dieron esa opción de poder seguir estudiando y poder terminar uma licenciatura. Investigador: Querer estudiar una licenciatura se debe a que necessitas mayor conocimiento para realizar tu trabajo, te sientes limitado en conocimiento o, ¿por qué quieres estudiar? Egresado: Mira, tú sabes perfectamente que el mundo es grandísimo; si te dijeran que vas a ser capturista y nada más tienes que aprender el sistema y meter los datos, bueno, pues igual ahí se acaba el conocimiento. Pero en un área que es contabilidad, finanzas, el mundo del conocimiento es bastante amplio, ¿no? Entonces, aunque tú terminaras una carrera, digamos en el Politécnico como contador público, siempre te estarían haciendo falta actualizaciones, más conocimientos, nuevas leyes, nuevas teorías, siempre hay que estar investigando, el conocimiento es muy amplio.

65 Apenas no dia 15 de abril de 1999, seis anos depois que se formou a primeira geração, se firmaram os Delineamento de Coordenação que permitem o trânsito de estudantes entre os subsistemas de institutos tecnológicos e de universidade tecnológicas. 
assim desejar, às opções de pós-graduação. A dimensão laboral se refere a regras tácitas e explícitas do sistema produtivo para selecionar, recrutar e promover o pessoal das empresas. Se o tabulador de uma empresa está baseado em critérios rígidos educacionais mais que no grau de conhecimento, então é difícil que um técnico superior universitário ocupe postos de alta hierarquia e, portanto, receba um salário maior. Isso mostra a necessidade de se fazer ajustes nas estruturas laborais - não somente nas educativas -, se, em verdade, se deseja melhorar o nível de vida dos indivíduos.

Quanto à dimensão social, se adverte sobre a complexidade para implantar estratégias para que o técnico superior universitário seja reconhecido dentro de sua sociedade e dos grupos de referência a que pertence. Porém não seria ilógico dizer que a estigmatização, que se faz no México, dos técnicos pode estar estreitamente relacionada com os problemas de tipo institucional e laboral. Se um técnico superior universitário é promovido em sua empresa, porque teve a facilidade de adquirir os conhecimentos - e a certificação - em uma instituição que operava eficientemente, então é mais provável que a sociedade (outros técnicos superiores universitários, pais de família, funcionários, empresários etc.) não faça distinções tão marcadas entre um técnico e um licenciado ou engenheiro. É preciso pensar detidamente as razões pelas quais, após 11 anos de sua criação, nas universidades tecnológicas, e com as custosas campanhas nacionais para difundir sua imagem, os egressos não tenham o "reconhecimento" que desejam.

É um fato que o cancelamento do tão mencionado segundo ciclo na Universidade Tecnológica de Nezahualcóyotl impediu aos alunos alcançar maiores realizações na sua formação, pelo que a liberdade para conseguir benefícios profissionais foi restringida e, com isso, a desigualdade de capacidades. Entretanto, isso parece afetar mais aos egressos que não tenham a capacidade econômica, o tempo e a facilidade de acesso a outras instituições educacionais para estudar uma licenciatura ou uma engenharia. Isso, como já foi dito, poderia segmentar o grupo de egressos da UTN em dois: 1) aqueles que podem pagar uma universidade privada ou transladar-se, na maior parte dos casos, à Cidade do México para frequentar alguma instituição educacional, e 2) aqueles que carecem dos meios para alcançar maiores capacidades.

\section{Reflexões finais}

Recorrer à perspectiva funcionalista ou estruturalista para a análise da relação entre educação e desigualdade traz o risco de omitir a forma como a 
ação dos indivíduos recria as estruturas sociais. Dado que a educação, como diz Paulo Freire, não é uma atividade neutra, mas uma forma de intervenção no mundo. Espera-se então que a pessoa que adquire conhecimento possa alcançar a capacidade para recriar, até certo ponto, os conglomerados sociais onde existe e atua.

A perspectiva das capacidades humanas, desenvolvida por Amartya Sen, abarca tanto a parte estrutural como a parte da agência humana para explicar a desigualdade, e conduz-nos a ampliar a visão sobre a forma como a educação e a desigualdade se relacionam. Se um ser humano carecesse das capacidades de que outro ou outros indivíduos possuem, então se estaria falando de fatores muito diferentes, como a desigualdade de oportunidades, de renda, de comida, de "bens primários" etc. Por isso é necessário centrar a atenção em três marcos gerais para avaliar a desigualdade de capacidades humanas: 1) as conquistas ou "realizações" das pessoas, 2) os meios para adquirir essas conquistas e 3) a liberdade para adquirir essas realizações (CALLINICOS, 2000).

Com base na perspectiva de Amartya Sen, o presente estudo revelou que a Universidade Tecnológica de Nezahualcóyotl representou uma possibilidade para adquirir conhecimentos e para melhorar as condições pessoais de seus egressos em um contexto de marcadas desvantagens educacionais, sociais, econômicas e culturais. Ter um espaço acadêmico que ofereça carreiras de curta duração, com um enfoque vocacional, foi um passo importante para a redução da desigualdade entre os moradores da cidade de Nezahualcóyotl.

$\mathrm{O}$ trabalho mostra claramente que os jovens que cursaram alguma carreira na UTN se encontram capacitados para obter uma posição laboral e receber um salário que sirva de base para a conquista de maiores capacidades, cujos egressos valorizam e tenham razão para valorizar. Emigrar de sua localidade, quando suas expectativas não são cobertas, recusar empregos que lesionam mais do que incentivam à conquista de outras realizações e estar motivado a continuar seus estudos, além do grau de técnico superior universitário, evidencia que são eles mesmos que traçam seus próprios caminhos para alcançar melhores níveis de bem-estar. Apesar de que a educação superior oferecida pela citada universidade desempenhe um papel muito importante na redução da desigualdade de capacidade, é necessário atender aos âmbitos institucional, político, social e econômico que rodeiam o espaço acadêmico. Ao restringir-se as oportunidades sociais e econômicas, cancela-se a possibilidade de adquirir maiores capacidades e, então, a desigualdade se acentua entre um grupo de pessoas com uma aspiração profissional similar, mas com rendas e situações laborais distintas.

Por último, cabe dizer que o desenvolvimento de investigações educacionais que utilizam a "complementaridade" entre a estrutura e a ação individual para explicar a desigualdade pode beneficiar substancialmente o desenho da 
política social no México, sobretudo, levaria a uma conquista de suma importância: compreender os seres humanos em uma perspectiva mais ampla.

\section{Agradecimentos}

A Deborah Fabri, a Arcelia Martínez, a Claudia Flores e ao professor Raff Carmen por sua leitura e seus pertinentes comentários à primeira versão deste artigo. Obrigada a Aída Flota por seu esmero na correção de estilo e ao meu amigo Salvador Ruiz de Chávez por seu incondicional apoio.

\section{REFERÊNCIAS}

ALVARADO, E. iA brazo partido! Historia de Cd. Nezahualcóyotl. México: Arenas editores, 1992.

AYALON, H.; GAMORAN, A. Stratification in Academic Secondary Programs and Educational Inequality in Israel and the United States. Comparative Education Review. vol. 44 (1), p. 54-80, 2000.

BARTOLUCCI, J. Desigualdad social, educación superior y sociología em México. México: CESU-UNAM, 1994.

BOWLES, S. Unequal Education and the Reproduction of the Social Division of Labor., en Karabel, J. y Halsey, A. H. (coord.). Power, Ideology in Education. Estados Unidos: OUP, 1977.

CALLINICOS, A. Equality. Inglaterra: Polity, 2000.

COLEMAN, J. S. Social Capital in the Creation of Human Capital. In: HALSEY, A. H.; LAUDER, H.; BROWN, P. y STUART, A. (Coord.). Education: culture, economy and society. Oxford-Nova York: OUP, 1997.

COORDINACIÓN GENERAL DE UNIVERSIDADES TECNOLÓGICAS (CGUT). Universidades Tecnológicas. Mandos medios para la indústria. México: CGUT-SEP, Noruega, 2000.

COORDINACIÓN GENERAL DE UNIVERSIDADES TECNOLÓGICAS (CGUT). Sitio electrónico. Acesso em 22 mar. 2002.

FLORES-CRESPO, P. La Universidad Tecnológica de Tula-Tepejí: entre la modernización y la desigualdade. In: IBARRA, E.; PORTER, L.; CAZÉS, D. (Coord.) Primer 
autoestudio de universidades públicas mexicanas. México: Centro de Investigaciones Interdisciplinarias en Ciencias y Humanidades-UNAM, 2002a.

FLORES-CRESPO, P. An Analysis of the Relationship between Higher Education and Development by Applying Sen's Human Capabilities Approach. The Case of Three Technological Universities in Mexico. Tese (Doutorado em Política). Universidade de York, Inglaterra. 2002b.

FREIRE, M. J. La igualdad de oportunidades en el acceso a la educación superior: Una perspectiva sociofamiliar para Galicia. Education Policy Analysis Archives, vol. 8 (20), 2000.

FREIRE, P. Politica y educación. México: Siglo XXI, 1996.

FREIRE, P. Pedagogía de la autonomía. Saberes necesarios para la práctica educativa. México: Siglo XXI, 1999.

FREIRE, P. Politica e Educação. São Paulo: Cortez, 2001.

GIDDENS, A. The Constitution of Society. Grã-Bretanha: Polity, 1989.

GOLDTHORPE, J. H. Problems of Meritocracy. In: HALSEY, HALSEY, A. H.; LAUDER, H.; BROWN, P. y STUART, A. (coords.), Education. Culture, economy and society. Grã-Bretanha: OUP, 1997.

INSTITUTO NACIONAL DE ESTADÍSTICA GEOGRAFÍA E INFORMÁTICA(INEGI). Los profesionistas en México. México: INEGI, 1993.

INSTITUTO NACIONAL DE ESTADÍSTICA GEOGRAFÍA E INFORMÁTICA(INEGI). Anuario estadístico del estado de México. México: INEGI, 1999.

LATAPÍ, P. Neoliberalismo y educación. In: Tiempo Educativo Mexicano. IV, México: UAA-UNAM, 1997.

LATAPÍ, P. Paulo Freire: in memoriam. In: Tiempo Educativo Mexicano. V, México: UAA, 1998.

MANTZAVINOS, C. Individuals, Institutions and Markets. Grã-Bretanha: Cambridge University Press, 2001.

MARSHALL, G. (Coord.). Diccionario Oxford de Sociología (2. edição). Grã- Bretanha: OUP, 1998.

MARTÍNEZ, L. Nezahualcóyotl: no bomba, ni hotel. México: Aries, 1986.

MUÑOZ IZQUIERDO, C. Origen y consecuencias de las desigualdades educativas. Investigaciones realizadas en América Latina sobre el problema. México: Fondo de Cultura Económica, 1996.

NUSSBAUM, M. Human Capabilities, Female Human Beings. In: NUSSBAUM, M.; GLOVER, J. (Coord.). Women, Culture and Development. A study of Human Capabilities. Grã-Bretanha: OUP, 1995. 
OBSERVATORIO CIUDADANO DE LA EDUCACIÓN (OCE). La educación superior ante un nuevo siglo. Comunicados, vol. I, México: OCE, 2000a

OBSERVATORIO CIUDADANO DE LA EDUCACIÓN (OCE). El Ceneval y su examen metropolitano. Comunicados, vol. I, México: OCE, $2000 \mathrm{~b}$.

OCDE. Reviews of National Policies for Education. Mexico, Higher Education. Paris: OCDE, 1997.

PAZ, O. La llama doble. Amor y erotismo. México: Seix Barral. Programa Nacional de Educación 2001-2006, México: SEP, 1993.

RESÉNDIZ, D. La vinculación de universidades y empresas: um asunto de interés público y privado. Revista de la Educación Superior. vol. 2 (106), p. 55-64, 1998.

ROWLANDS, J. Questioning empowerment: working with women in Honduras. Oxford: OXFAM, 1977.

SEN, A. Well-Being, Agency and Freedom. The Dewey Lectures 1984. The Journal of Philosophy, vol. LXXXII, n. 4, p. 169-224, 1985 a.

SEN, A. Commodities and Capabilities. Holanda: Elsevier Science Publishers, 1985b.

SEN, A. Inequality Reexamined. Grã-Bretanha: OUP, 1992.

SEN, A. Development Thinking at the Beginning of the 21st Century. Comunicação apresentada na conferência Development Thinking and Practice. Banco Interamericano, Washington, D.C. setembro, 1996.

SEN, A. Development as freedom. Grã-Bretanha: OUP, 1999.

SECRETARÍA DE EDUCACIÓN PÚBLICA(SEP). Universidad tecnológica. Una nueva opción educativa para la formación profesional a nivel superior. México: SEP, 1991a.

SECRETARÍA DE EDUCACIÓN PÚBLICA (SEP). Estudio de factibilidad para la creación de la Universidad Tecnológica de Nezahualcóyotl. México: SEP-Gobierno del estado de México, $1991 b$.

SECRETARÍA DE EDUCACIÓN PÚBLICA (SEP). Informe de labores 1998-1999. México: SEP, 1999.

SECRETARÍA DE EDUCACIÓN PÚBLICA (SEP). Perfil de la educación en México. México: SEP, 2000a.

SECRETARÍA DE EDUCACIÓN PÚBLICA(SEP). Programa Nacional de Educación 2001-2006. México: SEP, 2000b.

UNESCO. Summary of the World Declaration on Higher Education, 2000. Disponível em: $<$ http//:www.unesco.org/education/educprog/wche/summary.htm>. Acesso em set. 2001.

UNTERHALTER, E. The Capabilities Approach and Gendered Educations: An Examination of South African Contradictions. In: CONFERENCE ON JUSTICE AND 
POVERTY: Examining Sen's Capabilities Approach, junho 2001. Von Hugel Institute, St. Edmund's College, University of Cambridge, Inglaterra.

UNITED NATIONS DEVELOPMENT PROGRAMME. Human Development Report. Nueva York: OUP, 2000.

VILLA LEVER, L. Las políticas en educación superior en los años noventa. In: Las políticas sociales de México en los años noventa. México: Instituto Mora-UNAMFlacso-Plaza y Valdés, 1996.

WINCH, C.; GINGELL, J. (1999). Key Concepts in the Philosophy of Education. Londres: Routtledge, 1999.

Texto recebido em 23 de março de 2017. Texto aprovado em 13 de abril de 2017. 